\title{
Lesão queratocística em arco central mandibular. Uma região incomum
}

\section{Keratocystic lesion in the central mandibular arch. An unusual region}

\begin{abstract}
RESUMO
Introdução: De acordo com a OMS (2005) o queratocisto odontogênico, passou a ser classificado como Tumor Odontogênico Queratocístico, devido às suas características tumorais benignas, apresentando crescimento lento, insulflativo, sem provocar metástase ou infiltração acarretando destruição óssea, porém a OMS (2017) alterou novamente sua classificação para Queratocisto Odontogênico (QO). Esta reclassificação de 2005 teve como base a alta atividade proliferativa celular, o comportamento biológico localmente agressivo, o alto índice de recidiva e alterações no gene supressor de tumor PTCH porém mesmo com essa características o QO foi reclassificado devido sua capacidade de regressão espontânea. Objetivo: realizar uma discussão sobre o QO e seus tratamentos. Relato de caso: Paciente 47 anos, sexo feminino compareceu ao ambulatório da CTBMF, com queixa de aumento de volume em anterior de mandíbula gradual nos últimos 06 meses e migração dentaria, confirmados em exame físico intra-oral. O exame tomográfico mostrou lesão em anterior de mandíbula da região do dente 42 até a região do dente 34 medindo aproximadamente $20 \mathrm{~mm}$, imagem apresentando centro radiolúcido e halo radiopaco, tendo uma imagem compatível com lesão cística e abaulamento vestibular. A escolha de tratamento pela equipe foi realizar uma enucleação com osteomia periférica sob anestesia geral e realizada a opção de reconstrução com uma placa de reconstrução 2.4 do tipo locking afim de reforçar a região. Conclusão: A importância da localização de lesões satélites e uma correta escarificação do tecido ósseo local por meio de ostéctomia periférica diminui os indicies de recidivas frequentes das lesões queratocisticas que são comuns de ocorrerem.
\end{abstract}

\begin{abstract}
Introduction: According to WHO (2005), the odontogenic keratocyst is now classified as keratocystic odontogenic tumor, due to its benign tumor characteristics, presenting slow growth, insulflative, without causing metastasis or infiltration leading to bone destruction but the WHO (2017) again changed its classification to Odontogenic Keratocyst (OK). This reclassification at 2005 was based on the high cell proliferative activity, the locally aggressive biological behavior, the high recurrence rate and alterations in the tumor suppressor gene PTCH but even with these characteristics, the OK was reclassified due to its spontaneous regression capacity Objective: To conduct a discussion about OK and its treatments. Case Report: A 47-year-old female patient came to the outpatient clinic of the CTBMF, complaining of gradual anterior mandibular swelling over the last 6 months and tooth migration, confirmed by intraoral physical examination. CT scan showed a lesion in the anterior mandible from tooth 42 to tooth 34 measuring approximately $20 \mathrm{~mm}$, with a radiolucent center and a radiopaque halo, with an image compatible with cystic lesion and buccal bulging. The team chose to perform an enucleation with peripheral osteomy under general anesthesia and performed the option of reconstruction with a 2.4 locking-type reconstruction plate in order to reinforce the region. Conclusion: The importance of locating satellite lesions and correct scarification of the local bone tissue through peripheral ostectomy reduces the frequent recurrence rates of keratocystic lesions that are common to occur.
\end{abstract}

Keywords: queratocisto; mandibula; cisto odontogênico

\author{
Bianca de Fátima Borim Pulino ${ }^{1}$ \\ Raphael Capelli Guerra ${ }^{2}$ \\ Gabriel Cunha Collini ${ }^{3}$ \\ Guilherme Cunha Collini ${ }^{4}$ \\ Marcelo Vinicius Andrade Lima ${ }^{5}$ \\ Marcelo José Sanches ${ }^{6}$ \\ Eduardo Hochuli-Vieira ${ }^{7}$
}

${ }^{1}$ DDS, MSc, Doutoranda no Departamento de Diagnóstico e Cirurgia, Faculdade de Odontologia, Araçatuba, Universidade Estadual Paulista - Unesp, Brasil. Departamento de Cirurgia e Traumatologia Bucomaxilo Facial, Hospital Leforte/ Hospital e Maternidade Dr. Christovão da Gama, Santo André, Brasil;

${ }^{2}$ Aluno de Doutorando do Departamento de Diagnóstico e Cirurgia do Programa de Pós Graduação da Faculdade de Odontologia de Araraquara. FOAr UNESP. Chefe de Equipe de Cirurgia e Traumatologia Bucomaxilofacial do Grupo Leforte.

dr.raphael.guerra@gmail.com

${ }^{3}$ Professor Voluntário da Universidade Metodista de São Paulo.Membro de Equipe de Cirurgia

e Traumatologia Bucomaxilofacial do Grupo Leforte.

gabrielccollini@gmail.com

${ }^{4}$ Aluno Graduação da Universidade Metodista de São Paulo. cunha3320@gmail.com

${ }^{5}$ Professor Universidade Metodista de São Paulo. Professor da Universidade Guarulhos- UNG. marcelo.v.a.lima@gmail.com

${ }^{6}$ Professor da Universidade Metodista de São Paulo

${ }^{7}$ Professor Livre Docente, Adjunto do Departamento de Diagnóstico e Cirurgia do Faculdade de Odontologia de Araraquara. FOAr UNESP.

Membro de Equipe de Cirurgia e Traumatologia Bucomaxilofacial do Grupo Leforte.

eduardo.hochuli@unesp.br

Autor Correspondente:

Raphael Capelli Guerra

dr.raphael.guerra@gmail.com

raphael.guerra@unesp.br

+55 11 3375-9667

Rua Celso Ramos 86, apto 21. Vila Andrade,

São Paulo. Cep 05734-080

Submetido em: 24-2-2021

Aceito em: 21-10-2021 


\section{INTRODUÇÃO}

O termo "ceratocisto odontogênico" foi descrito pela primeira vez por Philipsen em 1956, sendo suas características relatadas apenas por Pindborg e Hansen em $1963^{1}$. O ceratocisto odontogênico possuiu a expressão cisto primordial como sinônimo, sendo classificado como cisto odontogênico até $2005^{1-6}$.

De acordo com a OMS (2005), o queratocisto odontogênico, antes considerado um cisto odontogênico (OMS-1992), passou a ser classificado como tumor odontogênico queratocístico, devido às suas características tumorais benignas, apresentando crescimento lento, insulflativo, sem provocar metástase ou infiltração acarretando destruição óssea ${ }^{1,3,5,7,10}$. Esta reclassificação teve como base a alta atividade proliferativa celular, o comportamento biológico localmente agressivo, o alto índice de recidiva e alterações no gene supressor de tumor PTCH ${ }^{1,2,9,10}$, porém em 2017 a OMS alterou novamente sua classificação para Queratocisto Odontogênico (QO) por que mesmo com as características citadas, neoplasias benignas não tem a capacidade de remissão espontânea com visto em alguns casos de descompressão.17

O QO tem a prevalência de $3 \%$ a $11 \%$ de todos os cistos odontogênicos, tendo sua prevalência na $1^{\text {a }}$ a $4^{\underline{a}}$ década de vida, acometendo mais o sexo masculino e a região posterior da mandíbula, mas quando presente na maxila, é mais frequente na região de terceiros molares ${ }^{1,2,4,6,8}$.

As características das imagens são descritas como áreas radiolúcidas com margens escleróticas bem definidas, sendo normalmente uniloculares e as lesões grandes podem se apresentar multiloculares. Um dente não erupcionado pode estar envolvido na lesão em $25 \%$ a $40 \%$ dos casos, podendo gerar dúvidas em relação ao diagnóstico preciso ${ }^{2,4,6}$.

\section{RELATO DE CASO}

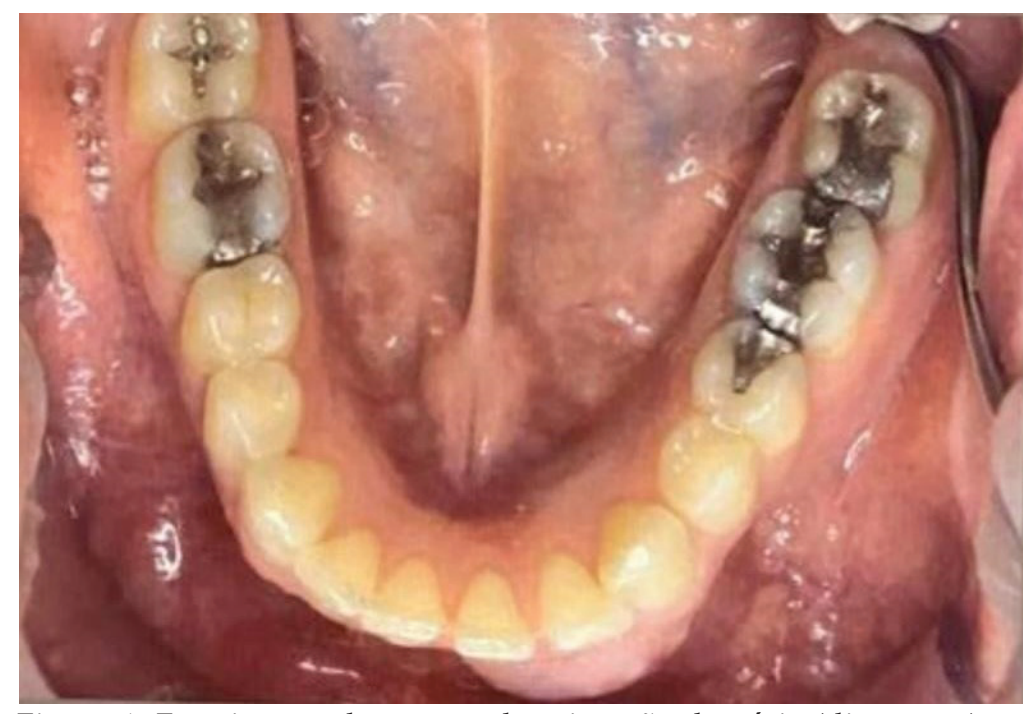

Figura 1: Foto intraoral, mostrando migração dentária (diastemas) entre os dentes 41, 31, 32 e abaulamento vestibular na região anterior de mandíbula.
Paciente P.R.F., 47 anos, sexo feminino, compareceu ao ambulatório de cirurgia e traumatologia Bucomaxilofacial do Grupo Leforte, com queixa de aumento gradual de volume na região anterior da mandíbula nos últimos 6 meses e migração dentária, confirmados no exame físico intraoral. Foi solicitada uma tomografia computadorizada para avaliar o tamanho da possível lesão e realizar um diagnóstico prévio. 
O exame tomográfico mostrou uma lesão na porção anterior da mandíbula na região entre os dentes 42 ao 34 , medindo aproximadamente $20,0 \mathrm{~mm}$. A imagem apresentava o centro radiolúcido e um halo radiopaco, sendo compatível com uma lesão cística e abaulamento vestibular.

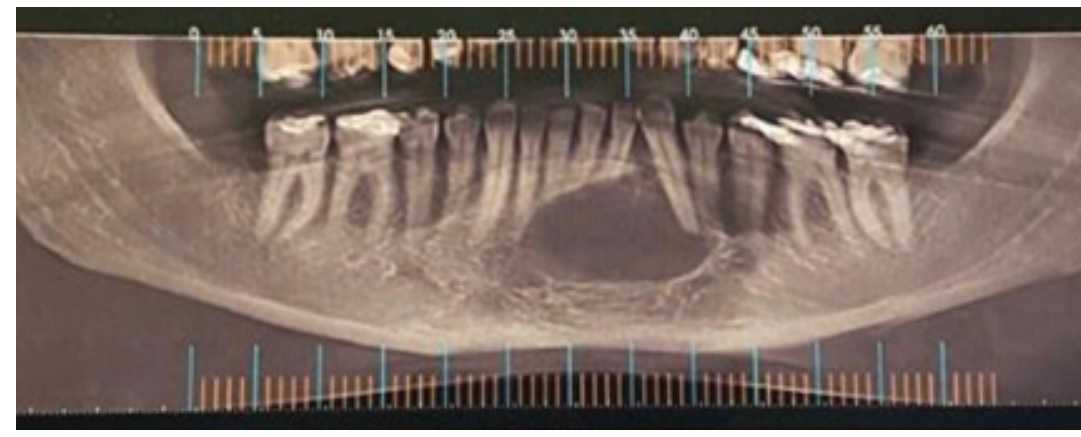

Figura 2: Radiografia panorâmica mostra uma lesão radiolúcida com halo radiopaco compatível com uma lesão cística em mandíbula.

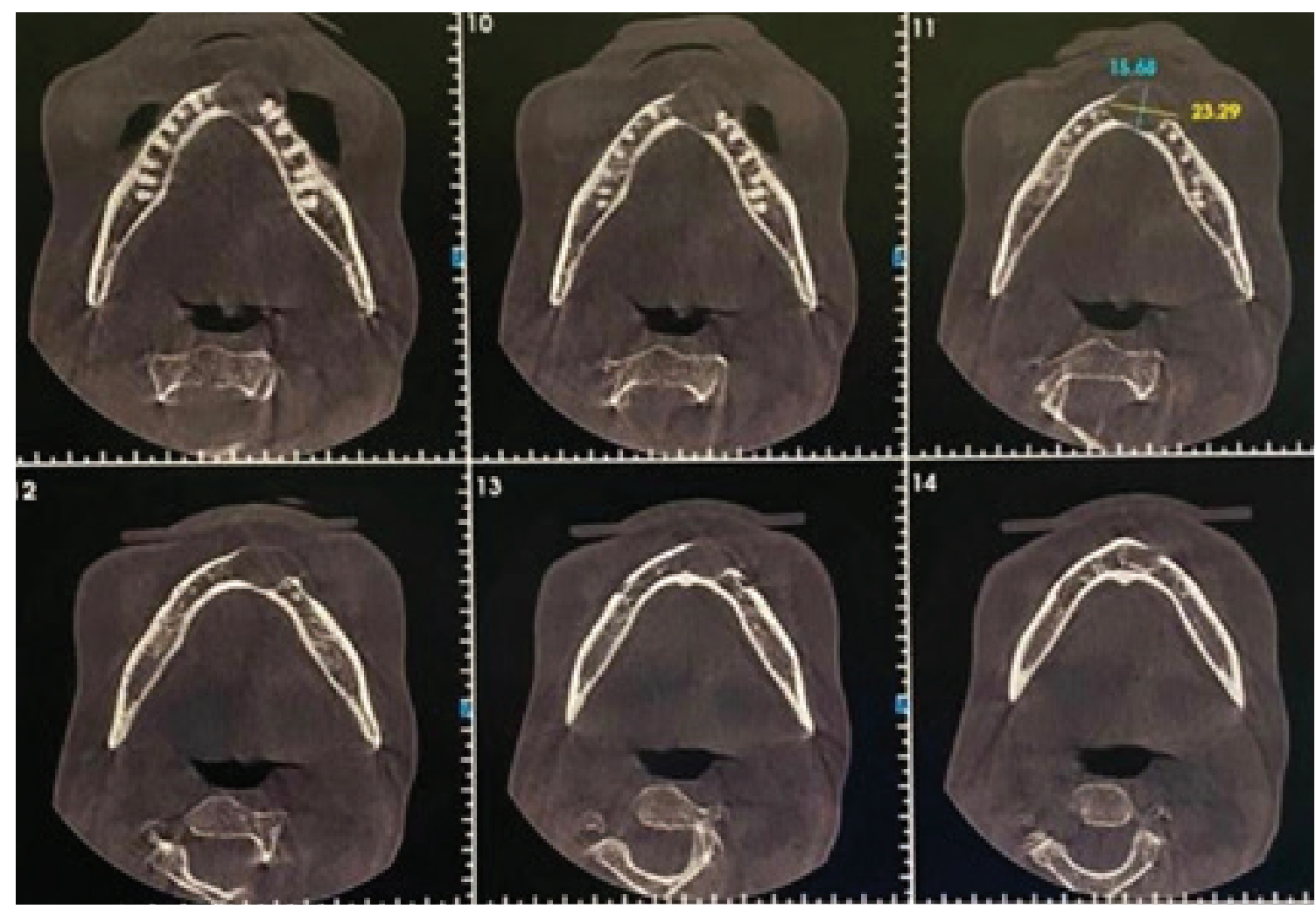

Figura 3: Corte axial tomográfico apresenta dimensões da lesão (23x15mm) e possível fragilidade da cortical lingual da mandíbula.

Foi realizada uma biópsia incisional, prévia a enucleação, em ambulatório, a fim de diagnosticar a lesão e excluir outras patologias, para definir o tratamento mais indicado para o caso. Após peça patológica ser submetida ao exame anatomopatológico concluiu se tratar de um QO, como consta no laudo. 


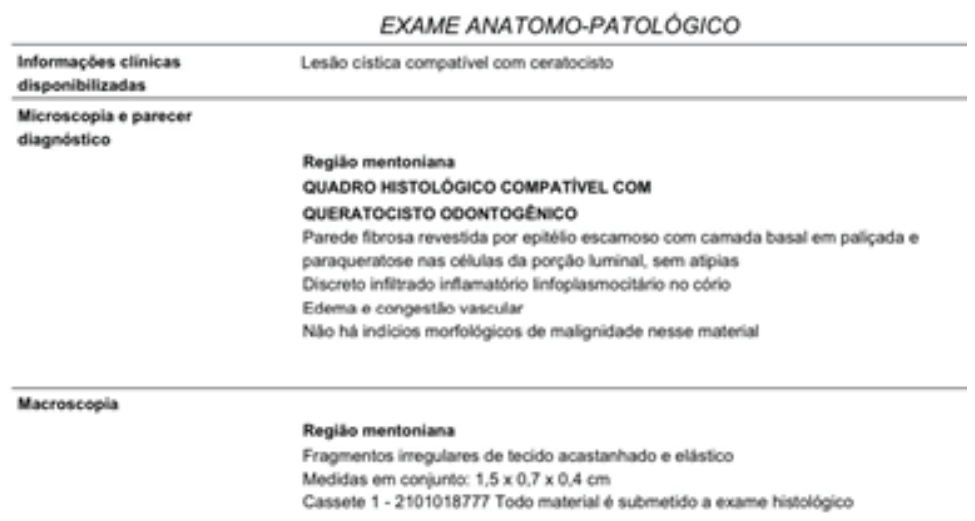

Figura 4: Laudo do exame anatomopatológico confirmando a presença de queratina na membrana cística, compatível com QO.

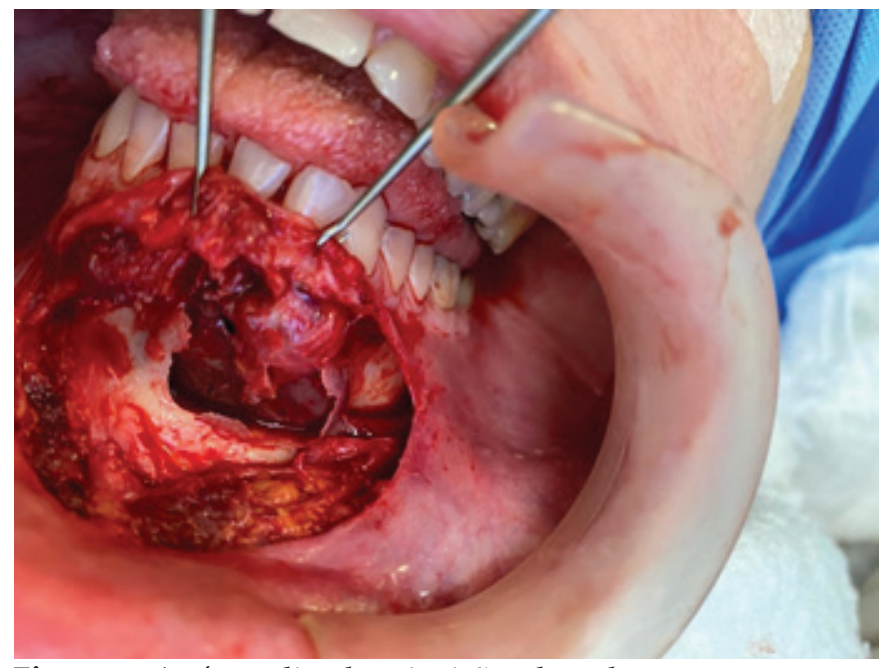

Figura 5: Após realizada a incisão, descolamento mucoperiostal e osteotomia. Enucleação da lesão e remoção da cápsula tumoral.

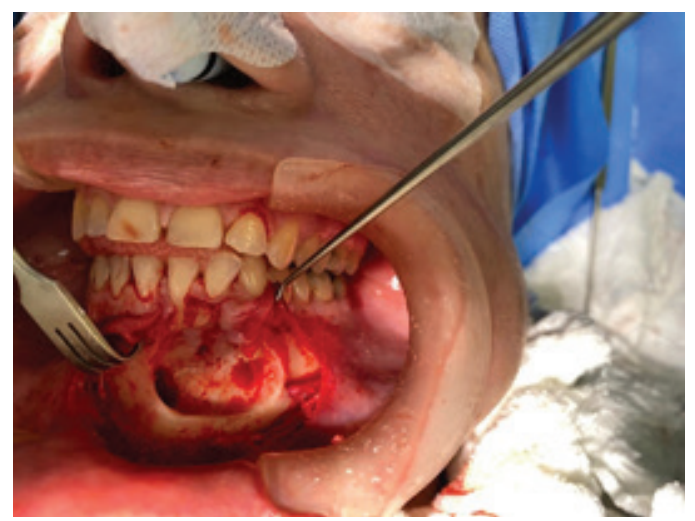

Figura 6: Loja cirúrgica após remoção da cápsula tumoral e osteotomia periférica, pode se observar múltiplas lojas tumorais.
Devido ao quadro a equipe a opção de realizar uma enucleação com osteotomia periférica sob anestesia geral. Inicialmente, foi realizada a infiltração de anestésico no fundo de sulco vestibular da região e subperiostal, a fim de facilitar o descolamento da membrana cística com o retalho. Posteriormente, foi realizada uma incisão tipo Wasmund em mucosa alveolar da região do dente 42 ao 35 e descolamento mucoperiostal.

Realizando osteotomia com broca 702 para acesso, enucleação da lesão e remoção da membrana do QO. Em seguida, feita osteotomia periférica com broca de desgaste, a fim de evitar a permanência de cistos satélites e restos da membrana da lesão, devido à alta taxa de recidivas em lesões desse tipo onde a osteotomia periférica e curetagem da loja se faz necessário devido a presença de paraqueratose aumentando a chance de recidiva.

Após realizada a osteotomia periférica, foi constatada a fragilidade da cortical lingual da mandíbula (fenestrações). Foi realizada a reconstrução com uma placa de 2.4 do tipo locking da Stryker ${ }^{\circledR}$ a fim de reforçar a região, pois além da má qualidade e quantidade óssea, a lesão se localiza em região de arco central mandibular, que é uma área muito susceptível a forças musculares 


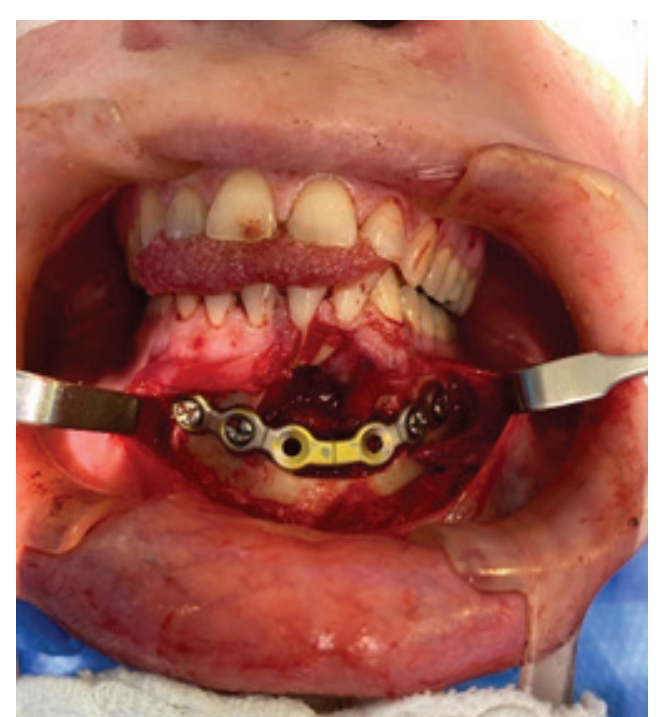

Figura 7: Colocação de fixação interna rígida: placa de 2.4 tipo locking da Stryker®. Nota-se a preservação do nervo mentual.

vetoriais de torção, havendo chances maiores de ocorrer fratura patológica no pós-operatório, seguindo assim os princípios de fixação interna estável.

\section{DISCUSS ÃO}

O QO pode apresentar um aumento de volume loco-regional, embora em lesões menores, possua um crescimento anteroposterior intraósseo assintomático, dificultando assim um diagnóstico prévio, sendo encontrado muitas vezes com exames radiográficos de rotina, como no caso relatado, onde ocorre abaulamento vestibular na região anterior da mandíbula. Devido as dimensões da lesão, é possível visualizar a migração dentária (fig. 1), sendo essa última situação não amplamente difundida na literatura ${ }^{4,6,14}$.

Em lesões maiores, porém, além do aumento de volume, podem apresentar dor, tumefação, edema, trismo muscular, pareste-

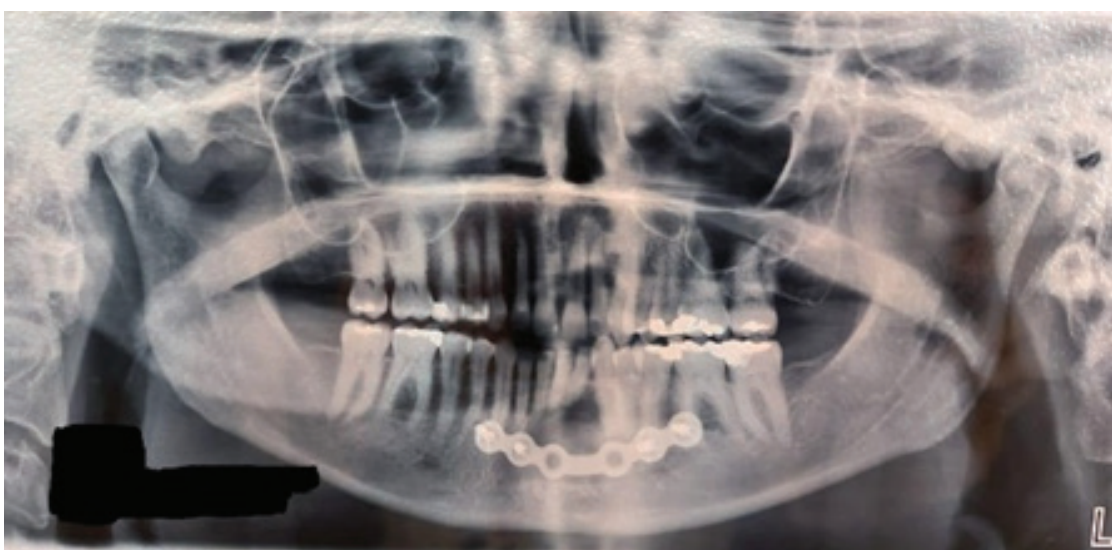

Figura 8: Radiografia panorâmica de controle com 7 dias de pós-operatório. sia, drenagem espontânea quando perfurada a cortical óssea e em casos avançados podem ocorrer fraturas patológicas, motivo por qual foi feita a opção pela colocação de fixação interna rígida no relato de caso. Entretanto, tumores extremamente grandes podem ser assintomáticos ${ }^{1,6,8,9,14,16}$.

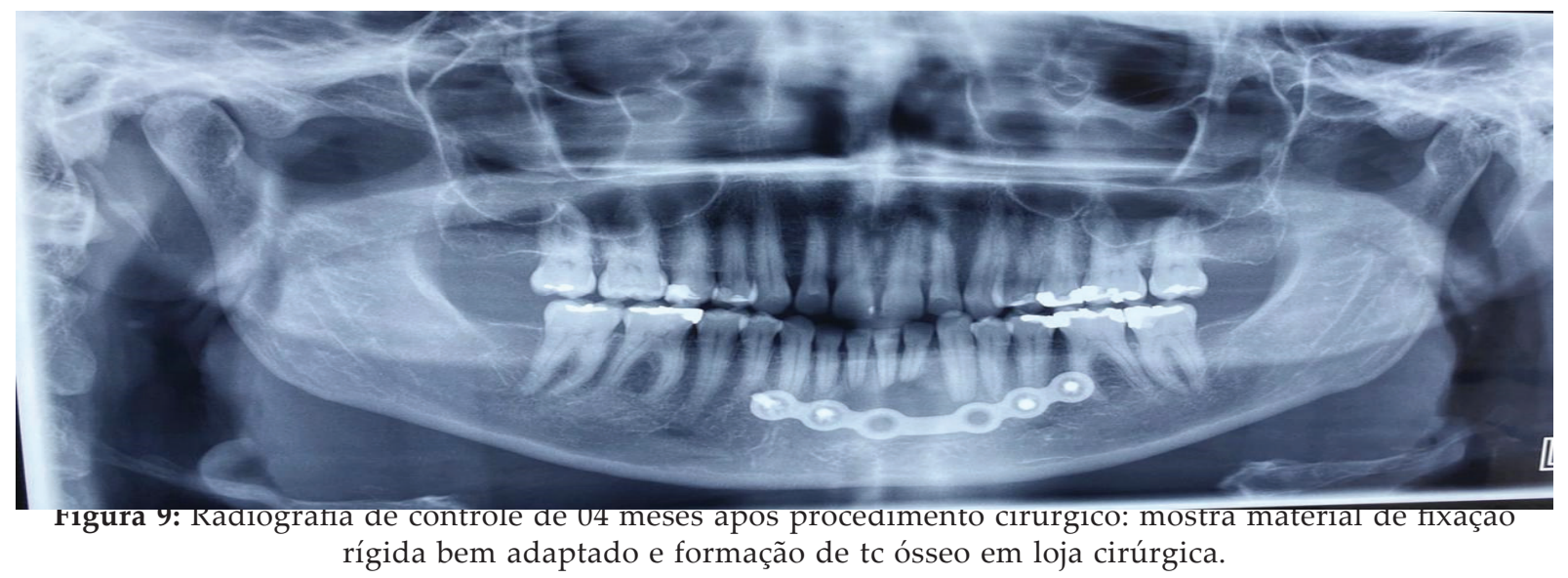


O QO é encontrado em sua maioria, na região posterior da mandíbula (corpo e ramo ascendente), com prevalência de $60 \%$ a $80 \%$ e na maxila tem prevalência para região de terceiros molares. Em $60 \%$ dos casos são acometidos pacientes da $1^{\underline{a}}$ a $4^{\underline{a}}$ década de vida, com o seu pico sendo relatado entre a $2^{\underline{a}}$ e $3^{3}$, com predileção pelo sexo masculino e uma prevalência de $77 \%$ pela raça branca ${ }^{1,2,4-6,11-14}$.

No relato de caso observa-se uma discordância com a literatura em relação a epidemiologia do QO. Esse caso se torna uma peculiaridade devido a paciente, embora estar na $4^{\underline{a}}$ década de vida, a lesão estar localizada em região anterior de mandíbula e ser do sexo feminino.

O tratamento preconizado para o QO é exclusivamente cirúrgico, onde diversos procedimentos são propostos, entre eles: enucleação seguida ou não de curetagem, descompressão, marsupialização, ressecção em bloco, ressecção com enxerto ósseo imediato e enucleação associada a procedimentos coadjuvantes. Para se definir a melhor forma de tratamento, devem-se considerar fatores com a idade do paciente, localização e tamanho da lesão e se o QO é primário ou recidivo ${ }^{2,3,14-16}$.

Para se evitar recidivas, procedimentos coadjuvantes são utilizados, como a osteotomia periférica, que é a remoção do osso circunvizinho a lesão com auxílio de broca cirúrgica, evitando a permanência de restos da membrana cística e com isso a recorrência da lesão. Alternativas coadjuvantes incluem a crioterapia após enucleação e aplicação da solução de Carnoy, por até três minutos pós enucleação. Esses procedimentos causam uma necrose química superficial do leito ósseo, evitando as chances de retorno da lesão ${ }^{1,6,13,15,16}$.

Levando em consideração a localização, tamanho da lesão e a idade da paciente, a equipe fez a opção de enucleação seguida de osteotomia periférica como preconizado na literatura. Devido a lesão não envolver estruturas nobres, não houve necessidade de descompressão ou marsupialização prévia, sendo optado pela osteotomia periférica para maior controle no desgaste ósseo, evitar necrose e injúria aos tecidos adjacentes e ao final, uma fixação estável com uma placa de reconstrução 2.4 com sistema de travamento placa-parafuso do tipo locking (fig. 7).

\section{CONCLUSÃO}

Com análise no caso e na literatura apresentada, podemos concluir que a correta anamnese, diagnóstico e tratamento do QO, se torna indispensável para o cirurgião-dentista obter a cura do paciente e evitar recidivas.

A importância da localização de lesões satélites e uma correta escarificação do tecido ósseo local por meio de osteotomia periférica, diminui os índices de recidivas frequentes das lesões queratocísticas, que são comuns de ocorrerem.

\section{REFERÊNCIAS}

1 - CARNEIRO, A.G.; CARDOSO, J.A.; DA SILVA, V.P.; BENIGNO, J.; CANCIO, A.V., FARIAS, J.G., Um ano de descompressão seguida de enucleação para tratamento de tumor odontogênico queratocístico: Relato de caso. Rev. Fac. Odont./ Univ. Passo Fundo, v. 17, n.02, Maio/Ago., p. 212-217, 2012.

2 - FAVERANI, L.P.; FERREIRA, G.R.; GODOY, P.; MELO, W.M.; FABRIS, A.L.S.; BASSI, A.P.F.; ARANEGA, A.M.; GARCIA JUNIOR, I.R. Tumor Odontogênico queratocístico - relato de caso. Rev. Bras. Cir. Cabeça Pescoço, v. 42, n. 03, Jul./Ago./Set., p. 172-175, 2013. 
3 - FONSECA, E.V., FRANZI, S.A.; MARCUCCI, M.; ALMEIDA, R.C., Fatores clínicos, histopatológicos e tratamento do tumor queratocisto odontogênico. Rev. Bras. Cir. Cabeça Pescoço, v. 39, n. 01, Jan./Fev./Mar., p. 57-61, 2010. 4 - LIMA, G.M., NOGUEIRA, R.L.M.; RABENHORST, S.H.B., Considerações atuais sobre o comportamento biológico dos queratocistos odontogênicos. Rev. Cir. Traumatol. Buco-Maxilo-Fac., v. 6, n. 02, Abr./Jun., p. 09-16, 2006.

5 - MOSCA, R.C.; PRADO, B.N.; VACCAREZZA, G.F., Keratocyst. A case report with characterization by CT. Rev. Odont. Da Universidade Cidade de São Paulo, v. 23, n. 02, Maio/Ago., p. 182-186, 2011.

6 - NEVILLE, B.W.; DAMM, D.D.; ALLEN, C.M.; BOUQUOT, J.E., Cistos e Tumores Odontogênicos. In: Patologia Oral e Maxilofacial, Rio de Janeiro : Elsevier, ed. 3ㄹ, p. 684-692, 2009.

7 RABELO, G.D.; HENRIQUES, J.C.G.; MACEDO, J.H.; SILVA, C.J.; CARDOSO, S.V.; LOYOLA, A.M.; DURIGHETTO JUNIOR, A.F., Non-syndromic keratocystic odontogenic tumor involving the maxillary sinus: Case report. Intl. Arch. Otorhinolaryngol., v. 14, n. 03, Jul./Ago./Set., p. 364-367, 2010.

8 - SCARTEZINI, G.R.; OLIVEIRA, G.C.; GUEDES, O.A.; DECURCIO, D.A.; CARVALHOSA, A.A.; ESTRELA, C., Diagnostic and treatment features of keratocystic odontogenic tumors. Stomatos, v. 18, n. 35, Jul./Dez. 2012.

9 - SILVA, M.M., Lesões primárias e recidivantes do tumor odontogênico queratocístico e cisto odontogênico ortoqueratinizado: casuística e análise histoquímica, imuno-histoquímica da proliferação celular e citoqueratinas. 2010. 71f. Tese (Doutorado em Odontologia) - Faculdade de Odontologia do Campus Araçatuba-UNESP, Araçatuba, 2010.

10 - RIBEIRO JÚNIOR, O., Estudo da terapêutica cirúrgica dos tumores odontogênicos queratocísticos associados ou não à síndrome do carcinoma nevóide de células basais e análise do tempo livre de recorrência. 2012. 126f. Tese ( Doutorado em Ciências Odontológicas) - Faculdade de Odontologia da Universidade de São Paulo, São Paulo, 2012. 11 - VAROLI, F.P.; COSTA, E.; BUSCATTI, M.Y.; OLIVEIRA, J.X.; COSTA, C., Tumor odontogênico queratocístico: Características intrínsecas e elucidação da nova nomenclatura do queratocisto odontogênico. J. Health Sci. Inst., v. 28, n. 01, Jan./Mar., p. 80-83, 2010.

12 - PEREIRA-SANTOS, D.; DE MELO, W.M.;BRÊDA-JR, M.A.; NOGUEIRA-SILVA, B.; SONODA, C.K.; HOCHULI-VIEIRA, E. Tratamento cirúrgico de tumor odontogênico queratocístico: Relato de caso. Rev. Bras. Cir. Cabeça Pescoço, v. 42, n. 03, Jul./Ago./Set., p. 169-171, 2013.

13 - MARQUES, J.A.F., NEVES, J.L.; ALENCAR, D.A.; LEMOS, I.M.; MARQUES, L.C., Ceratocisto odontogênico: Relato de caso. Sitientibus/ Univ, Est. Feira de Santana, n. 34, Jan./Jun., p.59-69, 2006.

14 - CARVALHO, A.C.G.S.; PEREIRA, C.C.S.; JARDIM, E.C.G.; GARCIA JÚNIOR, I.R.; FILHO, O.M., Tumor odontogênico queratocístico: Considerações clínico-cirúrgicas. Rev. Bras. Cir. Cabeça Pescoço, v. 41, n. 01, Jan./Fev./Mar., p. 36-38, 2012.

15 - JOHNSON, N.R.; BATSTONE, M.D.; SAVAGE, N.W., Management and recurrence of keratocystic odontogenic tumor: a systematic review. Oral and maxillofacial surgery, v. 116, n. 4, Out, p. 271-276, 2013.

16 - CHRCANOVIC, B.R.; GOMEZ, R.S., Recurrence probability for keratocystic odontogenic tumors: An analysis of 6427 cases. Journal of Cranio-Maxillofacial Surgery, v. 45, n. 2, Fev, p. 244-251, 2017.

17 - TOLENTINO, E.S, Updated WHO classification for odontogenic tumors: what has changed?. RFO, v. 23, n. 1, p. 119-123, jan./abr. 2018 